\title{
Gastric bronchogenic cyst presenting as a submucosal mass: a case report
}

\author{
Hassan Seddik ${ }^{1 *}$, Tarik Adioui ${ }^{1}$, Fadoua Rouibaa ${ }^{2}$, Fatima Zohra El Hamdi ${ }^{1}$, Aziz Aourarh², Mohammed Mahi ${ }^{3}$, \\ Ahmed Benkirane ${ }^{1}$ and Aziz Zentar ${ }^{4}$
}

\begin{abstract}
Introduction: Bronchogenic cysts are developmental anomalies of the primitive foregut which mostly occur in the lung. Gastric bronchogenic cysts are extremely rare; few cases have been reported in the literature and the diagnosis was often made following surgical resection.

Case presentation: A 40-year-old North African man was admitted to our hospital with a gastric submucosal mass. An endoscopic ultrasound revealed a unilocular cystic mass located in the muscular layer. Its content was echogenic suggestive of mucus. Magnetic resonance imaging confirmed the liquid nature of the cyst and showed a high ratio of proteins. Based on these observations, the diagnosis of bronchogenic cyst was confirmed. An endoscopic monitoring was decided rather than surgery because of the small size of the cyst and the absence of symptoms.

Conclusion: Although gastric bronchogenic cysts are rare, they should be well known and considered in all differential diagnoses of gastric tumors. We report a new case of gastric bronchogenic cyst and highlight the contribution of morphological tests that currently allow a non-invasive diagnosis.
\end{abstract}

Keywords: Bronchogenic cyst, Stomach

\section{Introduction}

Bronchogenic cysts are congenital anomalies evolving through the ventral foregut. They are the result of an autonomous and delayed development of a cell bud from the tracheobronchic tree. Bronchogenic cysts are divided into thoracic and abdominal cysts [1,2]. Abdominal bronchogenic cysts are rare, especially those located exclusively within the confines of the gastric wall. Few cases have been reported in the literature and the diagnosis was often made upon surgical resection [3]. We report a new case of gastric bronchogenic cyst and highlight the contribution of morphological tests that currently allow a non-invasive diagnosis.

\section{Case presentation}

A 40-year-old North African man was admitted to our hospital with an epigastric pain that had lasted for

\footnotetext{
* Correspondence: seddikhassan@yahoo.fr

'Department of Gastroenterology II, Mohamed V Teaching Military Hospital, Rabat 10100, Morocco

Full list of author information is available at the end of the article
}

6 months without dysphagia or hematemesis. His overall health condition was good and a clinical examination did not reveal anything notable except that the patient was slightly overweight. A gastroscopy revealed a submucosal mass, which was $2 \mathrm{~cm}$ in diameter, in the juxtacardial stomach (Figure 1). A histological examination did not help the diagnosis and revealed only Helicobacter pylori gastritis. An endoscopic ultrasound (EUS) confirmed the submucosal location of the lesion. It showed an image of a unilocular cyst containing echoic spots suggestive of mucus. This lesion was located in the muscular layer $45 \mathrm{~cm}$ from the dental arches and it measured $15 \times 19 \mathrm{~mm}$ (Figure 2). Magnetic resonance imaging (MRI) denoted a homogeneous hypersignal in sequences T1 and T2, with no enhancement after injecting the contrast agent, confirming the liquid nature of the cyst. It also showed a hypersignal $\mathrm{T} 1$ indicating a high ratio of proteins in the cyst content. Hydatic serology was negative. Based on the results of the morphological examinations, especially the MRI and EUS, the diagnosis of bronchogenic cyst was retained. We submitted the patient to $H$. pylori eradication therapy which stopped

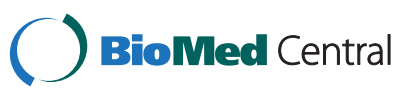




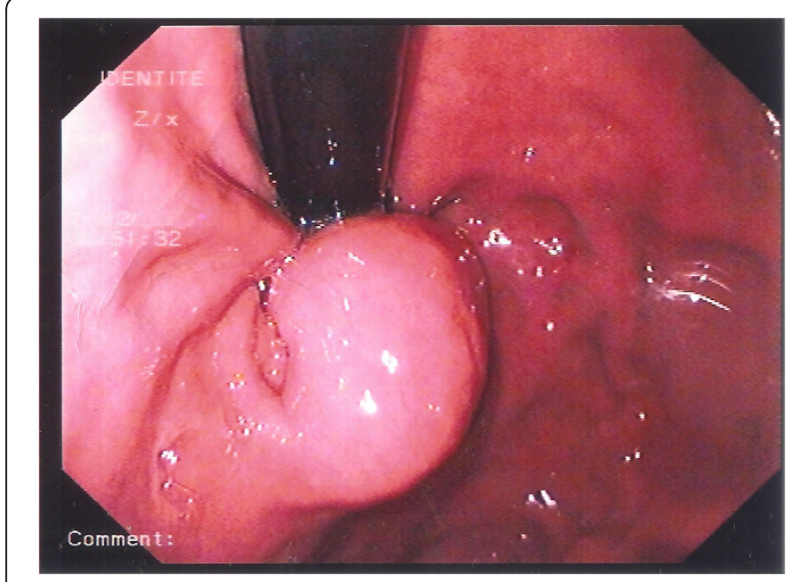

Figure 1 An esophagogastroduodenoscopy showed a submucosal mass in the patient's juxtacardial stomach.

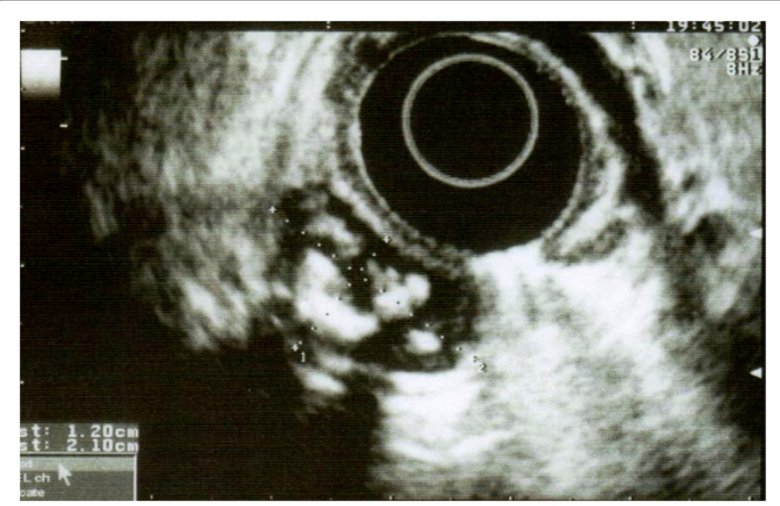

Figure 2 An endoscopic ultrasound showed a unilocular cystic lesion, developed in the muscularis, containing echogenic images.

his pain. We decided then to merely monitor the cyst due to its small size and the absence of symptoms.

Endoscopic controls realized during the following 3 years did not show any changes in the lesion aspect.

\section{Discussion}

Bronchogenic cysts located in the gastric wall are most often asymptomatic and discovered incidentally during a radiological or endoscopic test. The risk of further complication (intracystic bleeding, superinfection, compression) is not known in this location [3] whereas there is a high risk of further complications with pulmonary bronchogenic cysts. The morphology of gastric bronchogenic cysts may be misleading. In endoscopy they look like external compressions or submucosal masses suggestive of stromal tumor especially if located in the fundus. Usually, a histological examination also does not help the diagnosis. A computed tomography scan shows a round or oval-shaped mass, well-circumscribed and thin-walled, with fluid density and no enhancement after injecting the contrast agent. However, the lesion can be misdiagnosed as a solid mass in cases in which it contains thick mucinous and proteinaceous secretions [4]. An EUS test shows a hypoechoic or anechoic, wellcircumscribed, round or oval lesion which is located in the fourth hypoechoic layer of the gastric wall. Despite a good performance in terms of diagnosing gastric bronchogenic cysts, EUSs can sometimes be limited by the variability of the components of the cyst content. In the presence of thick fluid content, an EUS cannot exclude an encysted stromal tumor, which can also be located in the fourth hypoechoic layer and may contain intratumoral cysts. Some authors [5,6] suggest searching ciliated cells via a cytological study performed by an endosonographically-guided fine-needle aspiration. However, this aspiration can be challenging due to the thick content of the cyst and it may expose to superinfection of the cyst content [3,7]. The MRI was useful in the diagnosis [4] by showing homogeneous hypersignal in sequences $\mathrm{T} 1$ and $\mathrm{T} 2$, with no enhancement after injecting the contrast agent, confirming the liquid nature of the cyst. In our patient's case, confronting the results of the different morphological examinations allowed us to retain our gastric bronchogenic cyst diagnosis and we decided a mere endoscopic monitoring was sufficient treatment.

\section{Conclusion}

Although gastric bronchogenic cysts are rare, they should be well known and considered in all differential diagnoses of gastric tumors. We report a new case of gastric bronchogenic cyst and highlight the contribution of morphological tests that currently allow a noninvasive diagnosis.

\section{Consent}

Written informed consent was obtained from the patient for publication of this manuscript and accompanying images. A copy of the written consent is available for review by the Editor-in-Chief of this journal.

\section{Competing interests}

The authors declare that they have no competing interests.

\section{Authors' contributions}

$\mathrm{HS}$ and TA evaluated the patient and were major contributors to the writing of the manuscript. AA and FE performed the gastroscopy. FR performed the EUS. MM analyzed and interpreted the data from the MRI. $A B$ and $A Z$ reviewed the manuscript. All authors read and approved the final manuscript.

\section{Author details}

'Department of Gastroenterology II, Mohamed V Teaching Military Hospital, Rabat 10100, Morocco. ²Department of Gastroenterology I, Mohamed V

Teaching Military Hospital, Rabat 10100, Morocco. ${ }^{3}$ Department of Radiology, 
Mohamed V Teaching Military Hospital, Rabat 10100, Morocco. ${ }^{4}$ Department of General Surgery I, Mohamed V Teaching Military Hospital, Rabat 10100,

Morocco.

Received: 16 November 2011 Accepted: 21 June 2012

Published: 31 August 2012

\section{References}

1. Ribet M, Gosselin B, Watine O, Pruvot FR, Sault MC, Jarry JM: Congenital cysts of the esophageal wall with a respiratory type mucosa. Ann Chir 1989, 43:692-698.

2. Saviano MS, Bricoli A, Guarasci N, Guernelli N: Para-esophageal bronchogenic cysts. Lyon Chir 1986, 82:171-174.

3. Gillion JF, Lagneau M, Balaton A, Convard JP, Laroudie M, Hovasse D: Bronchogenic cyst of the juxtacardiol stomach mimicking a stromal tumor associated with a bronchogenic cyst of the subdiaphragmatic esophagus. Gastroenterol Clin Biol 2007, 31:1036-1038.

4. Baccialone J, Le Bevic T, Kremer S, Girodeau A, Ait-ameur A, Leclainche P, et al: Bronchogenic cysts in adults: natural history, general review, imaging and therapeutic news. Feuillets de Radiol 2002, 42:3-8

5. Sato M, Irisawa A, Bhutani MS, Schnadig V, Takagi T, Shibukawa G, et al: Gastric bronchogenic cyst diagnosed by endosonographically guided fine needle aspiration biopsy. J Clin Ultrasound 2008, 36:237-239.

6. Hall DA, Pu RT, Pang Y: Diagnosis of foregut and tailgut cysts by endosonographically guided fine-needle aspiration. Diagn Cytopathol 2007, 35:43-46.

7. Wildi SM, Hoda RS, Fickling W, Schmulewitz N, Varadarajulu S, Roberts SS Ferguson B, Hoffman BJ, Hawes RH, Wallace MB: Diagnosis of benign cysts of the mediastinum: the role and risks of EUS and FNA. Gastrointest Endosc 2003, 58:362-368.

doi:10.1186/1752-1947-6-262

Cite this article as: Seddik et al:: Gastric bronchogenic cyst presenting as a submucosal mass: a case report. Journal of Medical Case Reports 2012 6:262.

\section{Submit your next manuscript to BioMed Central and take full advantage of:}

- Convenient online submission

- Thorough peer review

- No space constraints or color figure charges

- Immediate publication on acceptance

- Inclusion in PubMed, CAS, Scopus and Google Scholar

- Research which is freely available for redistribution 